IIUC STUDIES

ISSN 1813-7733

Vol.-12 December 2015

(P. 101-110)

\title{
The Authenticity Gap between what is taught in Bangladeshi EFL Courses and the Reality of 'authentic' English
}

\author{
SawsanTarannum ${ }^{1}$
}

\begin{abstract}
The issueI intend to discuss in this paper is one that frustrates teachers and students alike. Bangladeshi students diligently practice their English for varying degrees of time and make varying amounts of progress but seem to run into insurmountable difficulties when confronted with 'native speaker' (NS) English. These difficulties stem from the seeming lack of convergence between the language being used by NSs and the language our students are practicing. In short, there is something of a 'gap' between what is taught in English conversation classes in Bangladesh, and the reality of 'authentic' English. This paper, therefore, briefly focuses on what is meant by the term 'authenticity gap' and the 'role of text books' in relation to this 'gap'. Problems associated with utilizing 'authentic English' in Bangladeshi classrooms will also be discussed in detail. Finally, there will be recommendations on how to bridge this gap.
\end{abstract}

\section{Background of the Study:}

Traditionally, in Bangladesh, the learners go to English conversation classes with an aim to learning English and preparing themselves for proficiency tests either to study abroad or migrate to any English speaking country. Specifically, students, often have, as their basic goal, the desire to achieve native like conversational skill. They want to empower themselves by gaining proficiency in speaking English, mainly for the interactional purpose. However, after many months, sometimes, years of study and much financial investment, many of them fail to achieve their goal. The learners become frustrated when they fail to get a desired job in their own country or face difficulties in communication when they move to any English speaking country. The gulf between their speech and the speech of NS is large and seemingly unassailable. "I'm fine, thank you, and you", is perhaps the best known example of the faux-English which appears in many textbooks and is taught to the students. There are many ways of opening a conversation, but in the context of Bangladesh, the classroom does not adequately represent the

\footnotetext{
${ }^{1}$ Assistant Professor of English, Centre for University Requirement Courses, International Islamic University
} Chittagong. 
range of language used by the NSs. It is to be noted that NS English differences are not only limited to phonological differences but also to grammatical differences and most importantly, differences in lexical choices. In Bangladesh, the paradigm shift from grammar translation to CLT approach could not bring any satisfactory change in English language teaching. The way students are taught English conversation does not prepare them to communicate in authentic native situations. Unfortunately, in the classroom and outside, our learners are not exposed to 'authentic English'. This makes them face numerous challenges when they move to English speaking countries and interact with the native speakers or with the speakers who use spoken grammar in conversation. Sometimes this lack causes communication breakdown between the interlocutors. For that reason, it is important to introduce more 'authentic' dialogues into the classroom.

\section{Authenticity Gap}

It is important to point out that the terms 'authentic' and 'native speaker' are both complex and controversial terms and difficult to explain satisfactorily within the constraints of this essay. Whereas, the term 'authenticity' here refers to the materials and the tasks chosen for English conversation classes in Bangladesh, 'authentic English' is used to indicate the naturally occurring language uttered by the native speakers of English. NS, in this essay, will refer to the speakers of American or British English.

Generally, there is always a 'gap' between the non-native speakers(NNS) and NS spoken language. This 'gap' is reality. Willis (1990) calls it 'TEFLese' -a language designed to illustrate the workings of a simplified grammatical system and bearing a beguiling but ultimately quite false similarity to real English. Burns (2001) points out most students encounter problems 'when they are faced with the task of interacting in an authentic social context outside the classroom'(p.124). Harmer (2001) lists the differences between the speech of NS and NNS such as intonation, lack of connected speech and expressive devices as well as other phonological and paralinguistic differences (p. 269). In the context of Bangladesh, the 'authenticity gap' is clear; the language of our English classroom does not adequately represent the language being used by NSs.

\section{Role of Text Books in Relation to 'Authenticity Gap'}

In relation to 'authenticity gap', the impact of textbooks plays a vital role. At the centre of the insistence on teaching 'authentic' English, a number of corpus-based studies confirmed that the language course 
books do not teach what native speakers really say. Textbook Dialogues may often be helpful to students as Swan (1984)notes, 'Scripted material is useful for presenting specific language items economically and effectively' (p.85). Non-authentic material can be used to help reinforce grammar targets but the lack of 'authenticity' means students are actually learning grammar patterns, not how to converse with NS, because native speakers generally do not converse in the way many of our textbooks depict. Rings (1992) notes that there is a potential danger 'of producing speakers of English who can only speak like a book, because their English is modeled on an almost exclusively written version of the language' (Cited in Carter and McCarthy, 1995, p. 207).

Carter (2003) notes that 'questions and answers sequences' for example, almost never occur in the way in which textbooks tend to depict them 'because they are accompanied by a follow up move in which, the third part, the questioner offers some kind of comment on or even evaluation of the answer'(p. 91).Carter, Hughes, and McCarthy (2005) also note that 'tails' are ignored by most grammars (p. 68) even though they occur frequently in corpus material. Sentences employing 'tails', such as 'I'm gonna have an old timer with cheese I am', 'She's lovely she is' (McCarthy and Carter, 1994, p. 212) illustrate the kind of language that is often excluded from traditional grammars. Carter and McCarthy (1995) add that even though subject and verb ellipsis is highly prevalent in the Nottingham corpus data the topic is treated as 'being of minor or secondary importance' in many standard grammar books (p.209). Williams (1988) criticizes textbook representations of business meetings and makes observations similar to McCarthy and Carter (1995) concerning the absence of 'authentic' spoken grammar. She notes that most of the spoken text collected, contained 'unfinished sentences, false starts, overlapping utterances, interruptions and fillers such as like, kinda, right, and you know. William (1988) added that, 'a large proportion of the language contained comments, jokes, quips, repetitions, and asides' (p. 49).

\section{Problems in Bangladeshi EFL Classrooms}

One problem with teaching 'authentic English' in Bangladeshi classrooms is the variability of constructed dialogues. Greetings, for example, are depended on the mood and the age of the speakers, their previous relationships as well as their gender. All of these factors can affect the speakers and cause them to alter their language slightly. The potential complexity of English could cause problems for textbook writers. However, this problem could also be seen as an opportunity for students to learn more about the cultural groundings of the language. It 
is also quite likely that students will recognize certain distinctions in forms of address and would be able to relate them to their mother tongue. This could hopefully aid students in viewing English as a 'real' living language rather than merely a subject to be studied. Bangladeshi students who attend conversation classes in different language learning centers often have a desire to improve their spoken English. However, instead of practicing NS norms of conversation, students are presented with 'culturally disinfected dialogues' (Carter, 2003, p.97).Many students express the desire to learn 'authentic' English, so why, on the whole, are they not permitted to do so?

Pronunciation may be seen as the source of incomprehensibility. Many Bangladeshi students have no exposure to contractions such as "gonna", "wanna" and "watcha" which are arguably more prevalent in spoken English than their non-contracted forms. However, this is only half of the problem. Regardless of phonology, students still have difficulty understanding NS speech. Another problem is the inability of many Bangladeshi students to understand what NSs are saying unless a considerable amount of code-switching is employed. Teachers often find it easier to adopt an unnatural style of speech in order to aid comprehensibility rather than attempt to alter students' spoken English patterns.

Many of the difficulties come from native speakers' using language or phrases that are unfamiliar to the students. At the same time, sometimes teachers are unaware of or not properly trained in the use of conversational grammar in the classrooms. So, introducing 'authentic' material into English classrooms is not a straight forward process. The debate surrounding 'authentic' English is far from resolved. Questions such as 'what constitutes authentic or real English?', 'Can authentic dialogue be transplanted to the EFL classrooms and retain its character?' and 'is “authentic” English useful for students?' are still being debated.

However, simplified versions of 'authentic' dialogues would possibly better prepare students for more 'authentic' communication. Introducing students slowly to features of spoken grammar as highlighted by Carter and McCarthy (1994) such as 'elision', 'false starts' 'tails' and 'fronting' would perhaps make the transition from classroom English to NS English somewhat easier. According to Ruhlemann (2008, p. 689), "It would appear that teaching learners how to use backchannels such as, 'yeah' and discourse markers such as, 'cos' might make their speech more natural and idiomatic". The use of spoken grammar in conversation gives the learners a certain 'flexibility' that facilitates communication (Timmis, 2005). 
"Despite advances in recording technology and available descriptions of naturally occurring conversations, dialogues produced for classroom use are for the most part scripted (McCarthy \& O'keeffe, 2004, p. 29). The textbooks employed in Bangladeshi English language institutes do not generally depict spoken English with much 'authenticity'. Burns (2001) notes that scripted dialogues rarely reflect the unpredictability and dynamism of conversation, or the features and structures of natural spoken discourse, and those students who encounter only scripted spoken language have less opportunity to extend their linguistic repertoires in ways that prepare them for unforeseeable interactions outside of the classroom (cited in McCarthy and O'keeffe, 2004). Technological advances have enabled the focus of EFL teaching to shift from written texts to spoken texts though grammar-translation approaches still have a huge influence on Bangladeshi language classrooms.

\section{Some Controversial Issues}

Corpus Material has made the task of finding examples of 'authentic' English much easier, but this new technology has not been received positively by all. Carter (1997) notes that technology may have improved our ability to analyze and examine authentic examples of spoken English but textbooks have largely failed to respond to this, employing idealized spoken texts.

Sinclair (2004) states that 'Corpus Linguistics... has no direct bearing on the way language may be presented in a pedagogical context...Corpus Linguistics makes no demands on the methodology of language teaching' (p. 79). While it may make no demands as such, corpus linguistics offers a rich vein of opportunity for teachers and textbook writers alike to explore. It is also worth adding that corpus material is not necessarily 'authentic' when it has been taken out of context. Hunston (2002)states that "language in a corpus is de-contextualized and must be re-contextualized in a pedagogical setting to make it real for learners” (p.193). This process of re-contextualization could certainly be problematic where cultural references and jokes are evident in the text. Even if we assume that corpus data used in a classroom setting can still be 'authentic' there is still no guarantee that it would be useful.

Another important question is that of whether or not NNS wish to sound like NS or if they are happy to use English merely as a lingua-franca. The fact that NNS' English is 'primarily Utilitarian in orientation' (Carter et al. 2005, p. 85) is certainly an important point. Most conversations held in English are between speakers whose first language 
is not English. Prodromou (1996) feels that NNS should sound like NNS but sounding like a NNS is as slippery a concept as sounding like a NS of British or American English. A Bangladeshi NNS would not share the same phonological, grammatical and lexical peculiarities as an Arab NNS. Nor do they share the same cultural background. Prodromou (1996, p.89) statesthat learning to speak English like an American or British native would involve learning their cultural attitudes and experiences. Of course, this cultural pose can merely be a mask that is worn by students and need not represent cultural imperialism. Jenkins (1998), an advocate of English as a lingua-franca,warns teachers to guard against deciding students' goals for them, 'in particular that they should not want to sound like native speakers if they clearly wish to do so' (p.12). Another interesting contribution to this debate is Timmis' (2002) questionnaire in which students were asked about their preferences regarding English. The results clearly show that many NNS wish to imitate 'NS' grammar, 'even the informal grammar native speakers' use when they speak to each other'(p.244).

It is irrelevant to ask the question whether students wish to speak NS English or not considering the pedagogical environment I have examined in this essay. In Bangladesh, inside the country students communicate with others in their L1. Majority of the students go to conversation classes to learn English mainly forgetting a good job in their home country or abroad, or to converse in English when they are abroad. So, standard American English or 'BBC English' would be perfectly acceptable. While Carter (2003) argues that ' 80 percent of all spoken interaction in English is between non-native speakers'(p.97) is valid, students wishing to learn English, for interactional not transactional purposes, for example chatting to foreign friends, may arguably be best helped by learning the kind of language they are likely to encounter in those situations. 'Students need to learn words and sentences not as isolated, planned answers to classroom exercises, but rather learn how to use these structures to create the flow and purpose of a spontaneously unfolding conversation' (Nattinger \& Decarrio, 1992, p. 113).It could perhaps be argued that Willis (1990) does indeed have a good point: having students practice 'TEFLese' instead of more authentic English could have a permanent negative influence on students.

If we can recognize that there is a problem and that often students' speech is not 'authentic', it implies that we are able to recognize something which is tangible and therefore teachable. It follows that if students wish to learn the kind of English that native speakers use, then 
they should not be denied that opportunity especially where students are paying customers, "at least for some purposes, the native speaker can be an interesting point of reference without being an object of deference" (Timmis, 2005, p. 124).

\section{Pedagogical Implications}

Although a totally satisfactory solution to the problems highlighted above is difficult to realize, there are certain actions teachers can take to make their students more aware of the gap between the English they are learning and the English that is spoken by NSs. One crucial component of this is consciousness-raising. Students need to be aware that the language they are learning is often different from NS norms and they need to know why. It is disappointing and de-motivating for students to realize that the English they spent years learning to speak is nothing like the English spoken by NSs. A good consciousness-raising exercise is to have students listen to examples of 'authentic' English dialogues like those featured in 'Exploring Spoken English'(Carter \& McCarthy,1997). This text contains recordings and transcriptions of NS conversations. It also contains activities drawing students' attention to certain features of 'spoken grammar'. Listening exercises could be built around passages starting with simply asking 'what are they talking about?' and moving up to a more complex analysis of the language.

Different types of authentic, situational tasks could be introduced to exploit students' awareness, noticing, and reactions. Activities could be designed by asking the students to predict and write about their experience of a particular interaction (e.g. telephone conversation and so on) in their L1 and English. After introducing authentic texts of that interactivity, students could be asked to compare their present learning with their prediction. These types of activities raise students' awareness and help to notice the similarities and differences between the conventions of two languages. Features such as 'heads', 'tails', 'tags', 'vague language', 'hyperbole', 'hedges' and 'collocation' could all be explored in the classroom and students could examine textbook examples of certain conversations and compare them to more authentic conversations. Burns (2001) also lists some useful ways in which 'authentic' language can be used in the EFL classroom including examining features of speech like, feedback, overlaps, discourse markers and turn-taking.

Ruhlemann, (2008) argues for the use of spokencorpora in the EFL classrooms, as it provides descriptive grammar and reveals 'gaps' between the spoken English used and taught in EFL classrooms and 
what is actually spoken by English users.Hunston(2002) describes how corpora material, can be used for consciousness-raising. Corpus material is useful with regard to collocation and the essentially learner-centered activity of having students search concordance lines. Corpus-material is learner centered because students can search for words and phrases and make their own conclusions about words through deductive reasoning. Insight into 'authentic' conversation patterns is also useful for teachers allowing them to develop lesson plans in which students are encouraged to use for example a $\mathrm{Q}+\mathrm{A}+1$ system. This involves teaching students that simply answering a question is not enough and that they should strive to give some kind of feedback. This approach may aid students with authentic questions and answers sequences. The analogy of a tennis game is useful to help students appreciate that without 'returning serve' the game would become very dull indeed.

Perhaps computers offer some potential for change; a Wikipedia style textbook based on corpus material might be one solution to the problems detailed in this essay. Wikipedia is an example of a computer encyclopedia that allows any user to edit the information and is subsequently more flexible than a textbook. If an encyclopedia of 'authentic English' was available on the web, it may aid users greatly with, for example, checking the validity of textbook conversations, searching for slang terms and working outside of class time. In certain Wikipedia, members can pose questions and receive answers and an 'in house' Wikipedia for Bangladeshi English language centers could give students greater access to 'authentic' English.

\section{Conclusion}

This essay has examined the use of 'authentic English' in EFL setting highlighting the gap between NS English and English used in Bangladeshi English conversation classrooms. Hence, the introduction of 'authentic' texts in Bangladeshi classrooms could certainly bring benefits and relieve certain frustrations mentioned in this essay. While there are undoubtedly problems with employing 'authentic' English, Swan (1984, p.82) points out that 'all other things being equal, authentic or natural-sounding dialogues are better models than artificial dialogues'.Widdowson (2000 cited in Ruhlemann, 2008, p. 688) perhaps made the right comment, "the language as realized by its users is the goal to which they aspire", at least; based on the goal of our learners, we should train them to use more 'authentic English' in conversation. Authentic English can be introduced in the classroom not only with the use of authentic materials but also with consciousness-raising activities and successful mediation through careful selection of those materials 
and motivating teaching. All these things may potentially benefit our learners to produce more natural and fluent utterances in conversations.

\section{References}

Burns, A. (2001). Analyzing spoken discourse: Implications for TESOL. In A. Burns\& C.

Coffin (Eds.), Analyzing English in a Global Context: A Reader,(pp. 123148).London: Rutledge.

Carter, R. (1997). Speaking English's speaks cultures, using CANCODE. Prospect, 12 (2), 4-11.

Carter, R. (2003). Orders of reality: CANCODE , Communication, and Culture. InB. Seidlhofer(ed), (pp. 90-104), Controversies in Applied Linguistics. Oxford: Oxford University Press.

Carter, R., Hughes, R. \& McCarthy, M. (2005). Telling tales: The spoken language and materials development. In B. Tomlinson (ed), (pp. 67-88), Materials Development in Language

Teaching. Cambridge: Cambridge University Press.

Carter, R. \& McCarthy, M. (1995).Spoken grammar: what is it and how can we teach it? ELT Journal,49(3), 207-218.

Carter, R.\& McCarthy, M.(1997). Exploring Spoken English. Cambridge: Cambridge University Press.

Harmer, J. (2001).The Practice of English Language Teaching (3rd edition). London: Longman.

Hunston, S. (2002).Corpora in Applied Linguistics. Cambridge: Cambridge University Press.

Jenkins, J. (1998). Which pronunciation norms and models for English as an international language? ELT Journal,52(2), 119-26.

McCarthy, M. \& Carter, R. (1994). Language as Discourse.New York: Longman.

McCarthy, M., \& O'Keeffe, A. (2004).Research in the teaching of speaking.AnnualReview of Applied Linguistics 24, 26-43.

Nattinger, J.\&DeCarrio, J. (1992). Lexical Phrases and Language Teaching. Oxford: Oxford University Press.

Prodromou, L. (1996). Correspondence. ELT Journal,50 (1), 88-91.

Rings, L. (1992).Authentic spoken texts as examples of language variation: grammatical,

situational and cultural teaching models. International Review of AppliedLinguistics30 (1), 21-33. 
IIUC Studies, Vol. 12

Ruhlemann, C. (2008). A register approach to teaching conversation: Farewell tostandard English? Applied Linguistics,29(4), 672-693.

Sinclair, J. (2004).How to use Corpora in Language Teaching.Amsterdam: John Benjamins Publishing Company.

Swan, M. A. (1984).Acritical look at the Communicative Approach.ELT Journal 56, 85-98.

Timmis, I. (2002). Native-speaker norms and International English: a classroom view.ELT

Journal, 56 (3), 240-249.

Timmis, I. (2005). Towards a framework for teaching spoken grammar.ELT Journal, 59 (2), 117-125.

Widdowson, H.(2000). On the limitations of linguistics applied.Applied Linguistics, 21 (1), 3-25.

Williams, M. (1988).Language Taught for Meetings and Language Used in Meetings: Is there Anything in Common.Applied Linguistics,9 (1), 45-58.

Willis, D. (1990).The Lexical syllabus.London: Collins. 